\title{
Hydroxyakalone, a Novel Xanthine Oxidase Inhibitor Produced by a Marine Bacterium, Agrobacterium aurantiacum
}

\author{
Hitoshi Izumida ${ }^{\dagger}$, Kyoko Adachi, Akira Mrhara ${ }^{\dagger \dagger}$, \\ TOHRU YasuzaWA ${ }^{\dagger \dagger}$ and Hiroshi Sano \\ Marine Biotechnology Institute, Shimizu Laboratory, \\ 1900 Sodeshi-cho, Shimizu-shi, Shizuoka 424, Japan \\ 'Kansai Paint Co., Ltd., Technical Research Laboratory, \\ 4-17-1 Higashi-Yawata, Hiratsuka 254, Japan \\ ${ }^{\dagger \dagger}$ Pharmaceutical Research Laboratories, Kyowa Hakko Kogyo Co., Ltd., \\ 1188 Shimotogari, Nagaizumi-cho, Shizuoka 411, Japan
}

(Received for publication May 12, 1997)

\begin{abstract}
A new xanthine oxidase inhibitor named hydroxyakalone was isolated from the culture broth of a marine bacterium Agrobacterium aurantiacum N-81106. Structure of hydroxyakalone was determined to be 4-amino- $1 \mathrm{H}$-pyrazolo[3,4-d]pyrimidine-3-one-6-ol by the spectral studies of hydroxyakalone and its permethyl derivative. The concentration to induce $50 \%$ inhibition $\left(\mathrm{IC}_{50}\right)$ was $4.6 \mu \mathrm{M}$ against xanthine oxidase.
\end{abstract}

Xanthine oxidase (XOD, EC 1.2.3.2) catalyzes the oxidation of hypoxanthine into uric acid via xanthine. It is well known that an excessive accumulation of uric acid in the blood, called hyperuricacidemia, causes gout. A number of XOD inhibitors such as anthraquinones ${ }^{1)}$, flavonoids ${ }^{2)}$, xanthones ${ }^{3)}$ and caffeic ester ${ }^{4)}$ have been found from plant sources.

In a previous paper ${ }^{5)}$, we reported a new XOD inhibitor, akalone from a marine bacteria, Agrobacterium aurantiacum N-81106. When cultivation conditions of A. aurantiacum N-81106 were changed using a 1000 liters fermenter, akalone was not produced, and another strong XOD inhibitor was found to be produced instead of akalone. In the present paper, we describe the fermentation, isolation and structural determination of this XOD inhibitor named hydroxyakalone.

\section{Materials and Methods}

\section{General}

The UV absorption spectrum was recorded on a Shimadzu UV-2100S recording spectrophotometer in distilled water, while NMR spectra were recorded with a Varian Unity 500 spectrometer using $\mathrm{D}_{2} \mathrm{O}$ and DMSO$d_{6}$ solvents. The FAB mass spectra (FAB-MS) were measured with a JEOL JMS-SX102 mass spectrometer.

\section{Fermentation}

Pre-incubated Agrobacterium aurantiacum N-81106 in a $500 \mathrm{ml}$ Elemenmeyer flask was inoculated into a 30-liter jar fermenter containing 18 liters of E3 medium composed of artificial seawater $500 \mathrm{ml}$, deionized water $500 \mathrm{ml}$, peptone $5.0 \mathrm{~g}$ (Kyokuto kogyo), yeast extract $1.0 \mathrm{~g}$ (Oriental yeast industry), glucose $2.0 \mathrm{~g}, \mathrm{FePO}_{4}$ $0.01 \mathrm{~g}(\mathrm{pH} 7.7$ before sterilization) and was incubated for 4 days at $20^{\circ} \mathrm{C}$. The resulting fermentation broth was inoculated into a 2000-liter large scale fermenter containing 1000 liters of the same medium and was incubated for 4 days at $20^{\circ} \mathrm{C}$.

\section{Assay Method}

Supernatant obtained from the fermentation broth by centrifuging at $18,600 \mathrm{~g}$ for 5 minutes was provided as a test solution. The bioassay for XOD inhibitory activity was performed according to a modified version of NORO's method $^{2)}$, using XOD from cow's milk that was obtained from Sigma Chemical Co. A mixture consisting of $0.3 \mathrm{ml}$ of test solution and $1.0 \mathrm{ml}$ of XOD solution, which was prepared at a concentration of 0.22 units $/ \mathrm{ml}$ with $50 \mathrm{mM}$ phosphate buffer, was pre-incubated for 15 minutes at $25^{\circ} \mathrm{C}$. The enzymatic reaction was initiated by adding to the mixture $1.7 \mathrm{ml}$ of substrate solution containing xanthine at a concentration of $1.74 \mu \mathrm{g} / \mathrm{ml}$. The optical density of the mixture was recorded at $290 \mathrm{~nm}$ by time scanning while incubating at $25^{\circ} \mathrm{C}$. A control mixture was also prepared in the same manner without the test solution. One unit of XOD activity is defined as that producing $1 \mu \mathrm{mol}$ of uric acid per min at $25^{\circ} \mathrm{C}$. The XOD inhibitory activity is expressed as the percentage inhibition of the enzyme and is calculated by the expression $(1-B / A) \times 100$, where $A$ and $B$ are the levels of XOD activity without and with test solution, respectively. 
Isolation of XOD Inhibitor

A 1000 liters sample of the fermentation broth of the Agrobacterium aurantiacum $\mathrm{N}-81106$ was filtered to remove solid materials. The solution was diluted by 2.5 times with distilled water and adjusted to $\mathrm{pH} 4.0$ with acetic acid. The solution was applied to an ion-exchange column [DIAION SK $104\left(\mathrm{H}^{+}\right), 50$ liters] and eluted with $2 \mathrm{~N} \mathrm{NH}_{4} \mathrm{OH}$. Active fraction was concentrated to 120 liters and was further purified on an ODS column (YMC ODS-AQ, 10 liters) eluting with water, followed by gel filtration (Sephadex G-25 column, 1 liter) eluting with ammonium acetate $(\mathrm{pH} 8.5)$. The active fraction was evaporated to dryness to give $158 \mathrm{mg}$ of hydroxyakalone as a colorless powder.

\section{Methylation of Hydroxyakalone}

To a suspension of hydroxyakalone (10 $\mathrm{mg}$ ) in DMF $(1 \mathrm{ml})$, silver (I) oxide $(460 \mathrm{mg})$ and methyl iodide $(95 \mu \mathrm{l})$ were added, and the mixture was stirred vigorously at $25^{\circ} \mathrm{C}$ for 4 days. The reaction mixture was filtered, washing the solids with chloroform. The filtrate was evaporated to give residue. An aqueous solution of the residue was applied to an ODS HPLC column (Cosmosil $\mathrm{C}_{18}$ AR, Nacalai Tesque, HPLC conditions: column size, $20 \mathrm{~mm}$ i.d. $\times 250 \mathrm{~mm}$; mobile phase, $50 \% \mathrm{CH}_{3} \mathrm{CN}$ with $0.1 \% \mathrm{TFA}$; flow rate $5 \mathrm{ml} /$ minute; detection UV 210 $\mathrm{nm})$. Evaporation of the major absorbing fraction gave $0.5 \mathrm{mg}$ of methylated hydroxyakalone as a colorless powder.

\section{Results and Discussion}

Structure of Hydroxyakalone

Physico-chemical properties of hydroxyakalone are summarized in Table 1. Hydroxyakalone is soluble in aqueous alkali and DMSO and insoluble in methanol, chloroform and $n$-hexane. Negative FAB-MS of hydroxyakalone showed a pseudo molecular ion $(\mathrm{M}-\mathrm{H})^{-}$ at $m / z 166$, and the molecular formula was determined to be $\mathrm{C}_{5} \mathrm{H}_{5} \mathrm{~N}_{5} \mathrm{O}_{2}$ on the basis of HR negative FAB-MS. The UV absorption spectrum showed a maximum at $298 \mathrm{~nm}$, and the ${ }^{13} \mathrm{C}$ NMR spectrum (Table 2) exhibited five $s p^{2}$ carbons, implying the existence of a conjugated heterocyclic system. The ${ }^{1} \mathrm{H}$ NMR spectrum in DMSO- $d_{6}$ showed five exchangeable protons, that is, there were no carbon-bonded protons. These data suggested that hydroxyakalone was an analog of akalone. However, no more information could be obtained from the spectra of the intact compound, and further investigation was carried out using the methyl derivative.

Methylation of hydroxyakalone with methyl iodide and silver oxide afforded several products. One of the products had the molecular formula $\mathrm{C}_{10} \mathrm{H}_{15} \mathrm{~N}_{5} \mathrm{O}_{2}$ which was indicated by HR FAB-MS (Table 1). The difference of molecular formulas between hydroxyakalone and its methylate suggested that five methyl groups were introduced into hydroxyakalone.

The five methyl groups introduced were assigned to be two $\mathrm{N}-\mathrm{CH}_{3}\left(\delta_{\mathrm{H}} 3.36, \delta_{\mathrm{C}} 31.20\right.$ and $\left.\delta_{\mathrm{H}} 3.21, \delta_{\mathrm{C}} 26.93\right)$, one $\mathrm{N}-\left(\mathrm{CH}_{3}\right)_{2}\left(\delta_{\mathrm{H}} 2.93, \delta_{\mathrm{C}} 40.36\right)$ and one $\mathrm{O}-\mathrm{CH}_{3}\left(\delta_{\mathrm{H}}\right.$ $\left.3.82, \delta_{\mathrm{C}} 53.91\right)$ groups by ${ }^{1} \mathrm{H}$ NMR, ${ }^{13} \mathrm{C}$ NMR and HSQC data. The HMBC spectrum showed long range couplings between the two $\mathrm{N}-\mathrm{CH}_{3}$ protons and the 6-carbonyl carbon, and between the 7- $\mathrm{NCH}_{3}$ protons and the 7a-carbon (Fig. 1), which confirmed the partial structure from N-5 to the 7a-carbon. A NOE was observed between $\mathrm{N}\left(\mathrm{CH}_{3}\right)_{2}$, which was long range coupled with $\mathrm{C}-4$, and $5-\mathrm{NCH}_{3}$, implying the bonding between N-5 and C-4. Since the neighboring atoms of the $s p^{2}$ quarternary carbon at $\delta_{\mathrm{C}} 104.35$ were carbons

Table 1. Physico-chemical properties of hydroxyakalone.

\begin{tabular}{|c|c|c|}
\hline & Hydroxyakalone & Methylated hydroxyakalone \\
\hline Appearance & Colorless powder & Colorless powder \\
\hline Molecular formula & $\mathrm{C}_{5} \mathrm{H}_{5} \mathrm{~N}_{5} \mathrm{O}_{2}$ & $\mathrm{C}_{10} \mathrm{H}_{15} \mathrm{~N}_{5} \mathrm{O}_{2}$ \\
\hline \multicolumn{3}{|c|}{ HRFAB-MS $(\mathrm{M}-\mathrm{H})^{-}(m / z)$} \\
\hline Calcd: & 166.0339 & \\
\hline Found: & 166.0365 & \\
\hline \multicolumn{3}{|c|}{ HRFAB-MS $(\mathrm{M}+\mathrm{H})^{+}(\mathrm{m} / \mathrm{z})$} \\
\hline Calcd: & & 238.1304 \\
\hline Found: & & 238.1302 \\
\hline $\mathrm{IR}(\mathrm{KBr}) \mathrm{cm}^{-1}$ & $3360,3088,1711,1616$ & $\begin{array}{l}3418,2926,2858,1702,1632 \\
\quad 1466,1377\end{array}$ \\
\hline $\begin{array}{l}\text { UV } \lambda_{\max } \\
\text { Solubility }\end{array}$ & $298 \mathrm{~nm}\left(\mathrm{H}_{2} \mathrm{O}, \mathrm{pH} 12.6\right)$ & $282 \mathrm{~nm}(\mathrm{MeOH})$ \\
\hline Soluble in: & $\mathrm{H}_{2} \mathrm{O}(\mathrm{pH} 12.6)$, DMSO & $\mathrm{MeOH}, \mathrm{CHCl}_{3}, \mathrm{DMSO}$ \\
\hline Insoluble in: & $\mathrm{MeOH}, n$-hexane, $\mathrm{CHCl}_{3}$ & $\mathrm{H}_{2} \mathrm{O}$ \\
\hline
\end{tabular}


Table 2. ${ }^{1} \mathrm{H}$ and ${ }^{13} \mathrm{C}$ NMR chemical shifts of hydroxyakalone $(\delta$ ppm).

\begin{tabular}{lc}
\hline${ }^{1} \mathrm{H}$ NMR (D $\left.\mathrm{O}\right)$ & No signal \\
${ }^{1} \mathrm{H}$ NMR (DMSO- $\left.d_{6}\right)$ & $11.0(\mathrm{br} .2 \mathrm{H}), 9.32$ (br. s $1 \mathrm{H})$ \\
& $6.40(\mathrm{br} . \mathrm{s} 2 \mathrm{H})$ \\
& $167.9,166.9,161.6,151.9$ \\
${ }^{13} \mathrm{C}$ NMR & 106.2 \\
\hline
\end{tabular}

Fig. 1. Partial structure of methylated hydroxyakalone and summarized results of HMBC and NOESY spectra of it.

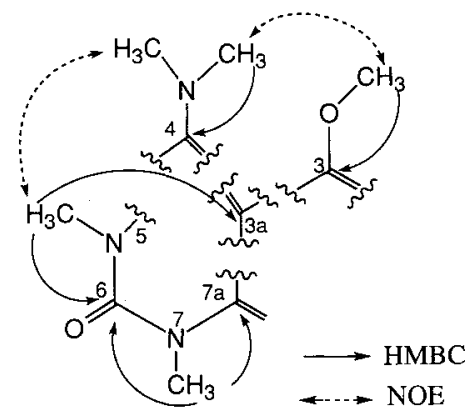

based on its chemical shift, the neighboring atoms must be $\mathrm{C}-4, \mathrm{C}-7 \mathrm{a}$ and $\mathrm{C}-3$. Thus, the connectivity of $\mathrm{C}-3$ to C-4 was established. A NOE between $\mathrm{N}\left(\mathrm{CH}_{3}\right)_{2}$ and $3-\mathrm{OCH}_{3}$, which was long range coupled with $\mathrm{C}-3$, also assisted this connectivity. The partial structure C-3 through C-7a contained all elements except two nitrogens. Thus the whole structure of methylated hydroxyakalone was determined to be as shown in Fig. 2 , introducing the remaining two nitrogens between the 3- and 7a-carbons. The chemical shifts of C-3, C-3a and C-7a were reasonable for this structure. In the HMBC study, ${ }^{4} J_{\mathrm{CH}}$ coupling was observed between $5-\mathrm{NCH}_{3}$ protons and the $3 \mathrm{a}$-carbon instead of ${ }^{3} J_{\mathrm{CH}}$ coupling with the 4-carbon. The total assignments of ${ }^{1} \mathrm{H}$ and ${ }^{13} \mathrm{C}$ NMR signals of methylated hydroxyakalone are listed in Table 3.

Owing to the establishment of the structure of methylated hydroxyakalone, the novel structure of hydroxyakalone was determined to be 4-amino- $1 H$ pyrazolo[3,4-d]pyrimidine-3-one-6-ol as shown in Fig. 2 where the 6-position of akalone is substituted by a hydroxy group. In its structure, a contribution of 6-one and 3-ol forms was thought to exist.

\section{XOD Inhibitory Activity of Hydroxyakalone}

Hydroxyakalone showed XOD inhibitory activity stronger than akalone. The $50 \%$ inhibition concentration $\left(\mathrm{IC}_{50}\right)$ of hydroxyakalone was $4.6 \mu \mathrm{M}$, compared with
Fig. 2. Structures of hydroxyakalone and its methylate.<smiles>Nc1nc(O)nc2[nH][nH]c(=O)c12</smiles>

Hydroxyakalone<smiles>COc1nnc2n(C)c(=O)n(C)c(N(C)C)c1-2</smiles>

Methylated hydroxyakalone
Table 3. ${ }^{1} \mathrm{H}$ and ${ }^{13} \mathrm{C}$ NMR assignments for methylated hydroxyakalone. (in DMSO, $\delta \mathrm{ppm}$ ).

\begin{tabular}{lrr}
\hline Position & Proton & Carbon \\
\hline 3 & & 158.99 \\
4 & & 151.24 \\
6 & & 154.39 \\
$3 \mathrm{a}$ & & 104.35 \\
$7 \mathrm{a}$ & & 151.16 \\
$3-\mathrm{OCH}_{3}$ & 3.82 & 58.91 \\
$4-\mathrm{N}_{3}\left(\mathrm{CH}_{3}\right)_{2}$ & 2.93 & 40.36 \\
$5-\mathrm{CH}_{3}$ & 3.36 & 31.20 \\
$7-\mathrm{CH}_{3}$ & 3.21 & 26.03 \\
\hline
\end{tabular}

$16.9 \mu \mathrm{M}$ for akalone and $4.0 \mu \mathrm{M}$ for allopurinol.

Acknowledgments

The authors are grateful to Mrs. Miho ARaki of Marine Biotechnology Institute for MS analysis.

\section{References}

1) Noro, T.; K. Noro, T. Miyase, M. Kuroyanagi, K. Umehara, A. Ueno \& S. Fukushima: Inhibition of xanthine oxidase by anthraquinones. Chem. Pharm. Bull. 35: $4314 \sim 4316,1987$

2) Noro, T.; Y. Oda, T. Miyase, A. Ueno \& S. Fukushima: Inhibitors of xanthine oxidase from the flowers and buds of Dephne genkwa. Chem. Pharm. Bull. 31: 3984 3987, 1983

3) Noro, T.; A. Ueno, M. Mizutani, T. Hashimoto, T. Miyase, M. Kuroyanagi \& S. Fukushima: Inhibitors of xanthine oxidase from Athyrium mesosorum. Chem. Pharm. Bull. 32: 4455 4459, 1984

4) Nakanishi, T.; M. Nishi, A. Inada, H. Obata, N. TANaBe, S. ABE \& M. Wakashiro: Two new potent inhibitors of xanthine oxidase from leaves of perilla frutescens britton var. acuta kudo. Chem. Pharm. Bull. 38: $1772 \sim 1774,1990$

5) Izumida, H.; K. Adachi, M. Nishijima, M. Endo \& W. Mikr: Akalone: A novel xanthine oxidase inhibitor produced by the marine bacterium, Agrobacterium aurantiacum sp. nov. J. Mar. Biotechnol. 2: 115 118, 1995 